\title{
A STUDY OF DUODENAL ULCER PERFORATION: RISK FACTORS AND PROGNOSTIC DETERMINANTS IN BTGH, GULBARGA
}

\author{
Rajshekhar Patil1, Sangamesh Kamthane², Palla Abhishek Reddy ${ }^{3}$
}

\begin{abstract}
${ }^{1}$ Associate Professor, Department of General Surgery, M. R. Medical College, Attached to Basweshwar Hospital, Gulbarga.
${ }^{2}$ Post Graduate, Department of General Surgery, M. R. Medical College attached to Basweshwar Hospital, Gulbarga.

${ }^{3}$ Post Graduate, Department of General Surgery, M. R. Medical College attached to Basweshwar Hospital, Gulbarga.
\end{abstract}

\begin{abstract}
BACKGROUND AND OBJECTIVES: Duodenal ulcer perforation is one of the acute abdominal emergencies in the surgical field. Duodenal ulcers are often caused due to imbalance between mucosal defences and acid /peptic injury. the cases of duodenal ulcer perforation in surgically treated patients were thoroughly studied with respect to trends in age, distribution of occurance, risk factors, seasonal variation, outcome of operative and non-operative modalities of treatment and factors influencing the prognosis of the disease. The current study summarizes epidemiology, risk factors, Pathophysiology, pathogenesis, clinical features, investigations, modalities of treatment and prognostic determinents of duodenal ulcer perforation in BTGH, Gulbarga.

MATERIAL AND METHODS: The study was conducted in the Department of Surgery, Basaveshwara Teaching and General Hospital, Gulbarga Karnataka during the period of Nov. 2011 - Sep.2013. The diagnosis of duodenal ulcer perforation was that established by the admitting surgeon, based on clinical features and supposed by radiological evidence and confirm at operation. Surgery was defined as urgent less as 4 hours between admission and surgery, same day (4-24 hours) and delayed at a later time during the same admission. This study comprises of 60 cases of duodenal ulcer perforation admitted in the Department of Surgery, Basaveshwar Teaching \& General Hospital. Operative details included the site and nature of operation performed. Mortality was defined as death following surgical procedure. Post-operative morbidity was defined in terms of duration of hospital stay and associated complications following surgery.

INCLUSION CRITERIA: All patients in whom a diagnosis of duodenal ulcer perforation was established on admission and confirmed by investigations between November 2011-September 2013 are included in this study.

EXCLUSION CRITERIA: 1. Cases of gastric antral perforation. 2. Cases of traumatic duodenal perforation.

RESULTS: out of 60 cases, the peak age incidence was between 40 and 49 years, only 3 cases of females with perforated duodenal ulcers were observed, 39 cases (65\%) belonged to lower socio-economic status, 57 males were either indulged with smoking $(40 \%)$ or alcohol $(30 \%)$ or both $(25 \%), 36$ patients $(60 \%)$ had previous history of peptic ulceration, NSAIDs intake was associated with $26.67 \%$, study the maximum incidence of perforation was during the four month of the winter 33 (66\%), 55 patients (91.67\%) had pneumo-peritoneum, 13 patients had wound infection and 7 out of them were expired.

CONCLUSION: A series of sixty cases duodenal perforations were studied and analyzed at Department of Surgery, Basaveshwara Teaching and General Hospital, Gulbarga Karnataka during the period of Nov 2011-Sep. 2013. The following is the list of the conclusions drawn after the study: 1. Duodenal ulcer perforation is one of the most common acute abdominal emergencies. 2. Duodenal ulcer perforation was more common in the age group of 40-49 years. 3. In this study the male: female ratio was found to be19:1. 4. Duodenal peroration was common in lower socioeconomic group. 5. The associated risk factors are found to be smoking, alcohol intake, NSAIDs intake and previous history of acid peptic disease. 6. Duodenal perforation cases were high during winter season. 7. Symptoms like abdominal pain and diarrhea were present in all patients with DU perforation. 8. Signs of G/R and BS were common in patients with DU perforation 9. Wound infection was common post-operative complications. 10. Mortality rate was higher in case of geriatric patients with comorbid illness. 11. Mortality rate in the age group of above 60 years is as high as 44.44\%. 12. Prognostic factors were, a. Age, b. Comorbid illness, c. Duration of symptoms, d. Delay in taking up the patient for emergency operation, e. Patient's general condition at the time of presentation.
\end{abstract}

KEYWORDS: Duodenal Ulcer Perforations, Simple Closure with Omental Patch Prognostic Factors, H. Pylari Prospective.

HOW TO CITE THIS ARTICLE: Rajshekhar Patil, Sangamesh Kamthane, Palla Abhishek Reddy. "A Study of Duodenal Ulcer Perforation: Risk Factors and Prognostic Determinants in BTGH, Gulbarga". Journal of Evolution of Medical and Dental Sciences 2015; Vol. 4, Issue 91, November 12; Page: 15657-15664, DOI: 10.14260/jemds/2015/2252.

INTRODUCTION: Duodenal ulcer perforation is one of the acute abdominal emergencies in the surgical field. Even though the incidence of peptic ulcer disease has been declining for past 20years and the need of elective ulcer

Financial or Other, Competing Interest: None.

Submission 19-09-2015, Peer Review 21-09-2015,

Acceptance 28-09-2015, Published 11-11-2015.

Corresponding Author:

Dr. Rajshekhar Patil.

Block No.56, Swastik Nagar,

Bilgundi Layout, Sedam Road,

Gulbarga.

E-mail:drrjsp@gmail.com

DOI:10.14260/jemds/2015/2252. surgery is on decline, neither the incidence nor the need for emergent complications of ulcer (Perforation, bleeding, obstruction) have changed during past 15-20 years.

Peptic ulcers are ulcers (Figure 1), occurring in any portion of the gastrointestinal tract (GIT), in which mucosa is bathed in hydrochloric acid ( $\mathrm{HCl}$ ) and gastric juice. Ulcers can develop in the esophagus, stomach or duodenum, at the margin of a gastroenterostomy, in the jejunum, and in association with a Meckel's diverticulum containing ectopic gastric mucosa. ${ }^{1}$ In older patients, admission rates for duodenal ulcer perforation increased in the last decade. Duodenal perforation currently accounts for approximately $75 \%$ of peptic perforation. In a recent study, a postoperative 
mortality rate of $19 \%$ in perforated peptic ulcer patients increased to $41 \%$ among the elderly. ${ }^{2}$

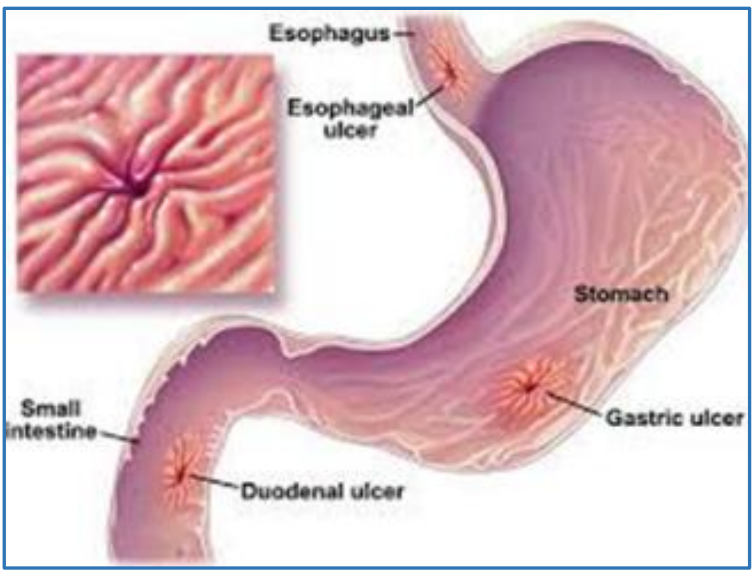

Fig. 1: Peptic Ulcers in Different Parts of Gastrointestinal Tract

With the success of medical therapy including potent gastric acid suppressing drugs and antibiotics effective against Helicobacter pylori, the need of surgical intervention has decreased drastically in the management of ulcer disease. ${ }^{3}$ Nonetheless, surgical operations remain the mainstay for the emergency treatment of life-threatening aggressive complications (Perforation, bleeding and obstruction) in duodenal ulcers at advanced stages.

With the success of medical therapy including potent gastric acid suppressing drugs and antibiotics effective against Helicobacter pylori, the need of surgical intervention has decreased drastically in the management of ulcer disease. $^{3}$ Nonetheless, surgical operations remain the mainstay for the emergency treatment of life-threatening aggressive complications (Perforation, bleeding and obstruction) in duodenal ulcers at advanced stages.

Following are the surgical options for duodenal ulcer perforations. ${ }^{4}$

- Operations for duodenal ulceration reduce acid production by the stomach.

- Cephalic phase reduced by vagotomy.

- Antral phase reduced by antrectomy.

- May require gastric drainage procedure to overcome effects of vagotomy.

Duodenal ulcers are often caused due to imbalance between mucosal defenses and acid/peptic injury. ${ }^{5}$ Following are the causes for duodenal ulcer perforations (Figure 2):

- Increased gastric acid secretion.

- Helicobacter pylori infection.

- Smoking.

- Alcohol consumption.

- Psychological stress.

- Drugs such as NSAIDs, Aspirin, cocaine.

- Genetic factors.

- Impaired defensive properties of the mucosa and barrier mechanism.

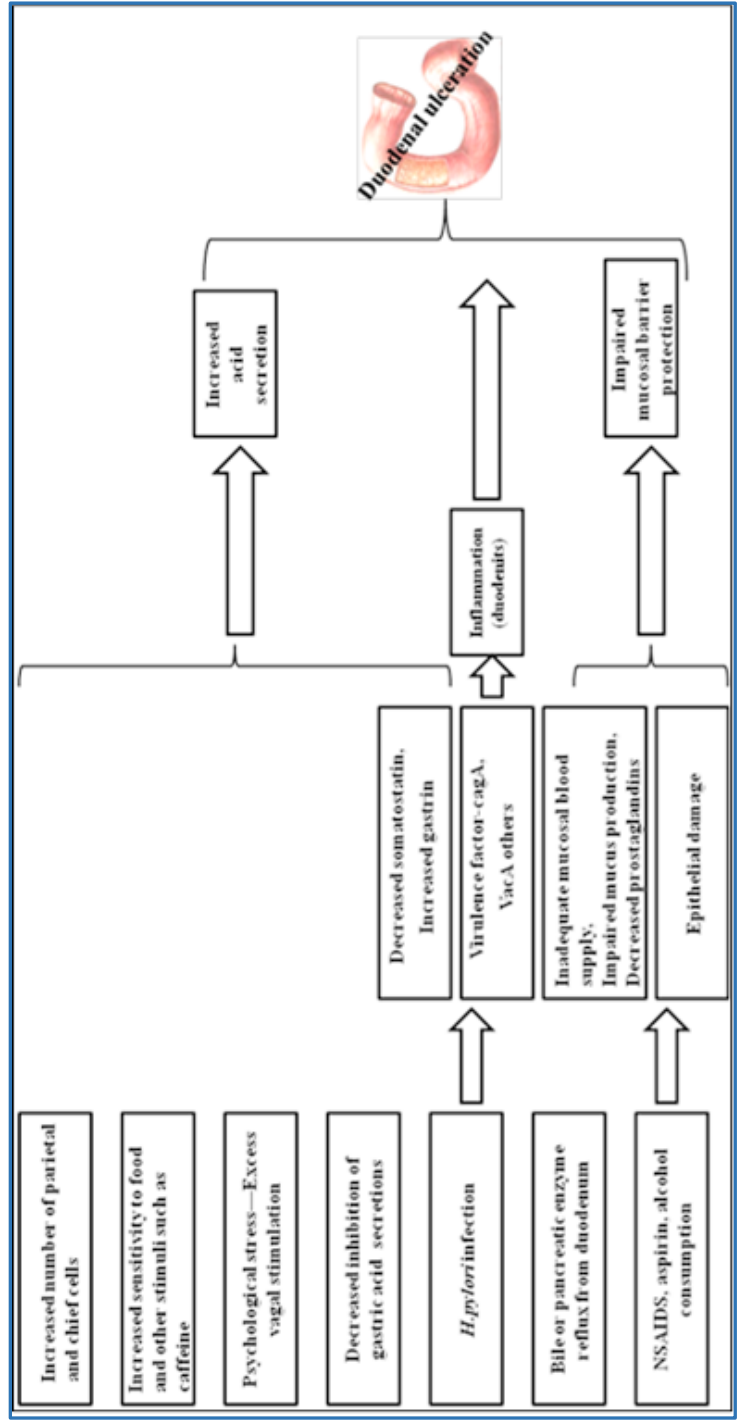

Fig. 2: Pathogenesis of Duodenal Ulceration

The present study deals with duodenal ulcer perforation in patients treated surgically. The cases of duodenal ulcer perforation in surgically treated patients were thoroughly studied with respect to trends in age, distribution of occurrence, risk factors, seasonal variations, outcome of operative and non-operative modalities of treatment and factors influencing the prognosis of the disease.

The current study summarizes epidemiology, risk factors, pathophysiology, pathogenesis, clinical features, investigations, modalities of treatment and prognostic determinants of duodenal ulcer perforation in BTGH, Gulbarga. There are multiple factors influencing the progress of the disease and its prognosis which would be discussed in detail in this study.

\section{AIMS AND OBJECTIVES:}

The aims of the study are:

1. To study the prevalence of duodenal ulcer perforation with respect to age.

2. To study the risk factors and seasonal trends.

3. To study the prognostic factors influencing the disease process.

4. To study the outcome of operative and non-operative treatment - mortality and morbidity. 
MATERIALS AND METHODS: The study was conducted in the Department of Surgery, Basaveshwara Teaching and General Hospital, Gulbarga Karnataka during the period of Nov. 2011 - Sep. 2013. The diagnosis of duodenal ulcer perforation was that established by the admitting surgeon, based on clinical features and supposed by radiological evidence and confirm at operation.

Surgery was defined as urgent less as 4 hours between admission and surgery, same day (4-24 hours) and delayed at a later time during the same admission. This study comprises of 60 cases of duodenal ulcer perforation admitted in the Department of Surgery, Basaveshwar Teaching \& General Hospital. Operative details included the site and nature of operation performed. Mortality was defined as death following surgical procedure.

Post-operative morbidity was defined in terms of duration of hospital stay and associated complications following surgery.

Inclusion Criteria: All patients in whom a diagnosis of duodenal ulcer perforation was established on admission and confirmed by investigations between November 2011September 2013 are included in this study.

\section{Exclusion Criteria:}

1. Cases of gastric antral perforation.

2. Cases of traumatic duodenal perforation.

RESULTS: Sixty cases of duodenal ulcer perforation were studied. In all 55 cases underwent simple closure and omnetal Patch (SC \& OP) and the perforation were found in the anterior aspect of first part the duodenum. All cases were advised to continue anti-H.pylori treatment for 4 weeks post-operatively. The following observations were made out.

\section{Gender:}

\begin{tabular}{|c|c|c|}
\hline Gender & No. of cases & Percentage (\%) \\
\hline Male & 57 & 95 \\
\hline Female & 3 & 5 \\
\hline Total & $\mathbf{6 0}$ & $\mathbf{1 0 0}$ \\
\hline \multicolumn{2}{|c|}{ Table 1: Table showing gender distribution } \\
\hline
\end{tabular}

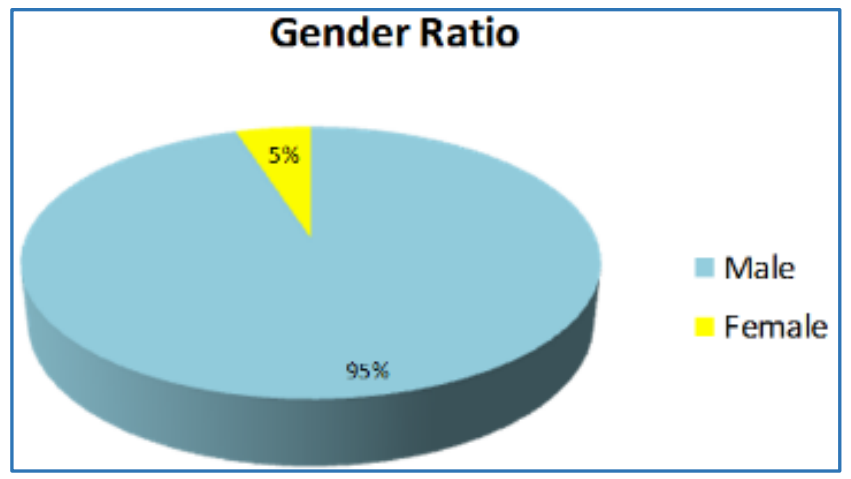

Chart 1: Pie diagram showing gender distribution

Socioeconomic Status:

\begin{tabular}{|c|c|c|}
\hline & No. of Cases & Percentage\% \\
\hline Lower & 39 & 65 \\
\hline Upper & 21 & 35 \\
\hline Total & $\mathbf{6 0}$ & $\mathbf{1 0 0}$ \\
\hline \multicolumn{2}{|c|}{ Table 2: Socioeconomic Status } \\
\end{tabular}

\section{Socioeconomics Status}

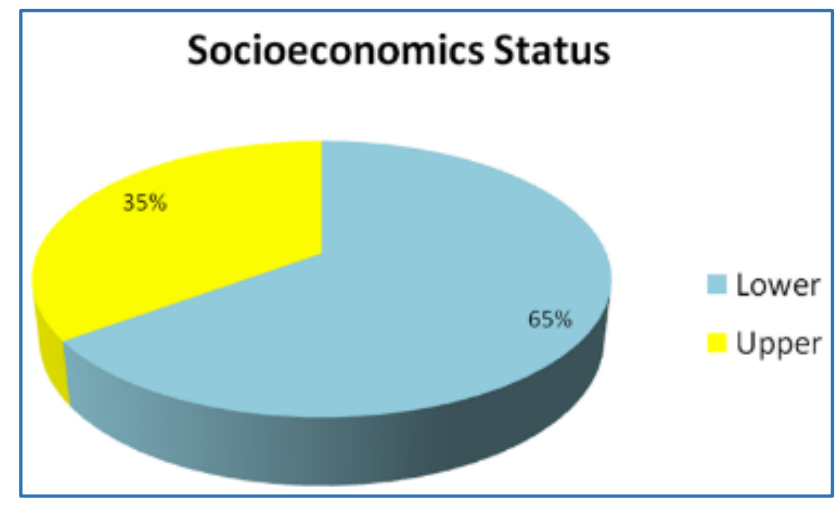

Chart 2: Pie diagram showing distribution of socioeconomic status

Personal Habits:

\begin{tabular}{|c|c|c|}
\hline Habits & No. of Cases & Percentage (\%) \\
\hline Smoking & 24 & 40 \\
\hline Alcohol & 18 & 30 \\
\hline Both & 15 & 25 \\
\hline None & 3 & 5 \\
\hline Total & $\mathbf{6 0}$ & $\mathbf{1 0 0}$ \\
\hline \multicolumn{2}{|c|}{ Table 3: Personal habits of patients with perforated } \\
duodenal ulcerss
\end{tabular}

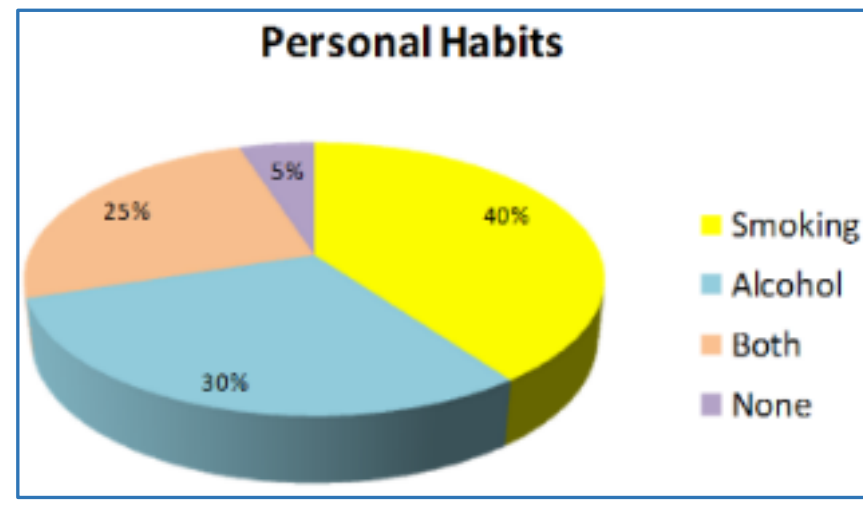

Chart 3: Pie diagram showing personal habits of Patients with perforated duodenal ulcers

\section{History of Acid Peptic Disease:}

\begin{tabular}{|c|c|c|}
\hline History & No. of Cases & Percentage (\%) \\
\hline Present & 36 & 60 \\
\hline Absent & 24 & 40 \\
\hline Total & $\mathbf{6 0}$ & $\mathbf{1 0 0}$ \\
\hline \multicolumn{2}{|c|}{ Table 4: History of acid peptic disease of patients } \\
with perforated duodenal ulcers
\end{tabular}

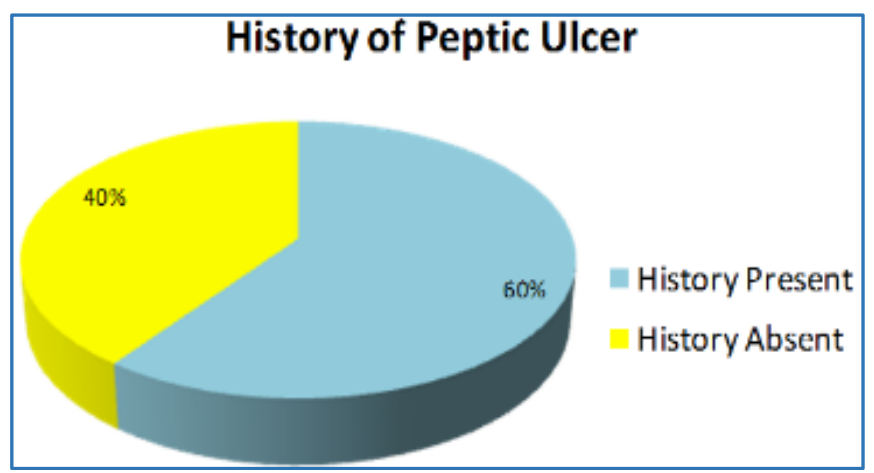

Chart 4: Pie diagram showing History of acid peptic ulcer 
History of Drug Intake:

\begin{tabular}{|c|c|c|}
\hline & No. of Cases & Percentage (\%) \\
\hline $\begin{array}{l}\text { History of NSAIDs } \\
\text { Intake }\end{array}$ & 16 & 26.67 \\
\hline $\begin{array}{l}\text { No History of NSAIDs } \\
\text { Intake }\end{array}$ & 44 & 73.33 \\
\hline Total & 60 & 100 \\
\hline \multicolumn{3}{|c|}{$\begin{array}{c}\text { Table 5: History of NSAIDs intake in patients } \\
\text { with perforated duodenal ulcer }\end{array}$} \\
\hline
\end{tabular}

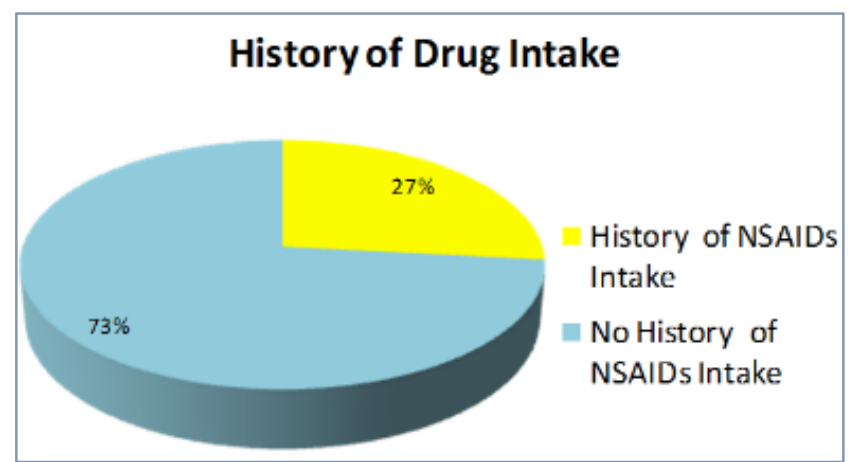

Chart 5: Pie diagram showing History of NSAIDs intake by Patients

\begin{tabular}{|c|c|c|c|}
\hline $\begin{array}{c}\text { Age } \\
\text { (yrs.) }\end{array}$ & $\begin{array}{c}\text { Cases without } \\
\text { NSAIDs intake }\end{array}$ & $\begin{array}{c}\text { Cases with } \\
\text { NSAIDs intake }\end{array}$ & $\begin{array}{c}\text { Percentage } \\
\text { (\%) }\end{array}$ \\
\hline$<30$ & 15 & 2 & 12.5 \\
\hline $30-39$ & 12 & 1 & 6.25 \\
\hline $40-49$ & 15 & 3 & 18.75 \\
\hline $50-59$ & 9 & 4 & 25 \\
\hline$>60$ & 9 & 6 & 37.5 \\
\hline Total & $\mathbf{6 0}$ & $\mathbf{1 6}$ & $\mathbf{1 0 0}$ \\
\hline \multicolumn{4}{|c|}{ Table 6: Age distribution of patients with and without } \\
history of NSAIDs intake( $\boldsymbol{X}^{2}-\mathbf{5 . 7 3}$, p<0.05(p=0.043) \\
\hline
\end{tabular}

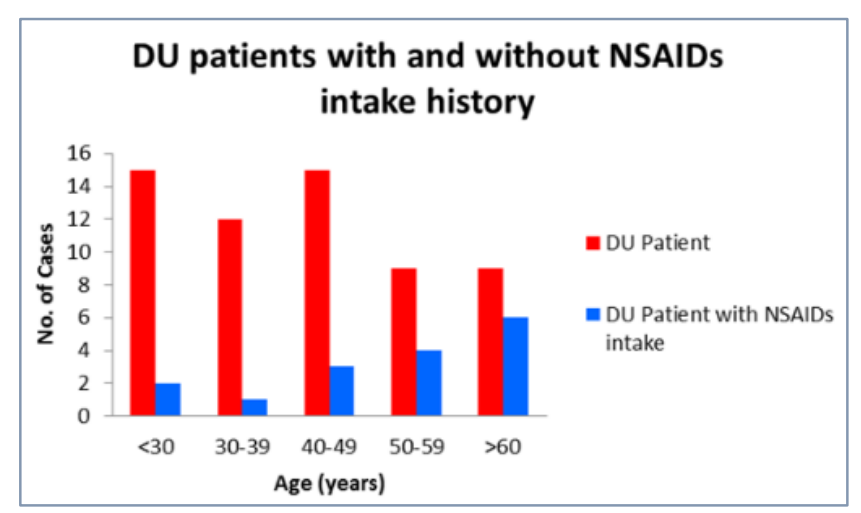

Chart 6: Age distribution of patients with and without history of NSAIDs intake

Seasonal Trends:

\begin{tabular}{|c|c|c|c|}
\hline Months & Seasons & No. of Cases & $\begin{array}{c}\text { Percentage } \\
\text { (\%) }\end{array}$ \\
\hline Feb.-May & Summer & 9 & 15 \\
\hline June-Sept. & Monsoon & 18 & 30 \\
\hline Oct.-Jan. & Winter & 33 & 55 \\
\hline & Total & $\mathbf{6 0}$ & $\mathbf{1 0 0}$ \\
\hline \multicolumn{3}{|c|}{$\begin{array}{c}\text { Table 7: Seasonal trends } \\
(X 2-14.7, \boldsymbol{p}<0.001(p-0.00089)\end{array}$} \\
\hline
\end{tabular}

Seasonal Trend

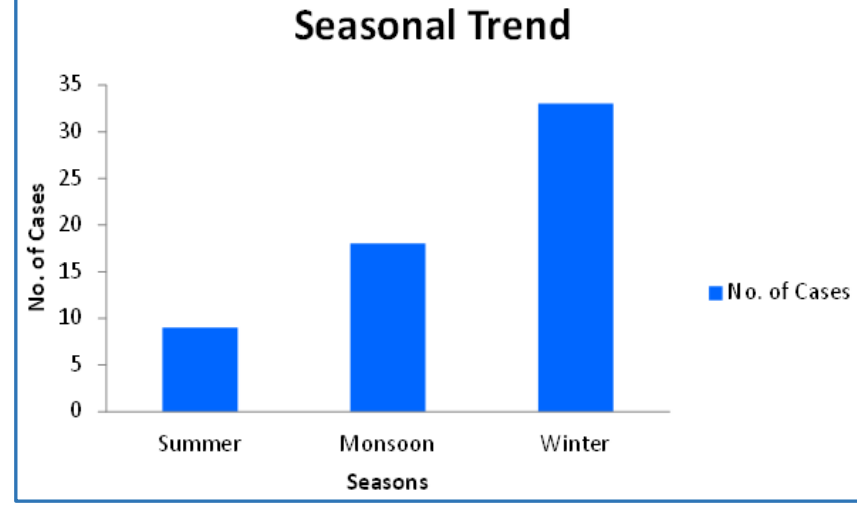

Chart 7: Graph showing seasonal trend observed in perforated duodenal ulcers

Investigations:

\begin{tabular}{|c|c|c|c|c|}
\hline Investigations & $\begin{array}{c}\text { No. of } \\
\text { Cases(+) }\end{array}$ & $\begin{array}{c}\text { No. of } \\
\text { Cases (-) }\end{array}$ & Total & $\begin{array}{c}\text { Sensitivity } \\
\text { to test }\end{array}$ \\
\hline X-Ray & 55 & 5 & 60 & 91.7 \\
\hline USG & 60 & 0 & 60 & 100.0 \\
\hline
\end{tabular}

Table 8: Investigations test for duodenal ulcer perforation

\begin{tabular}{|c|c|c|}
\hline & No. of Cases & Percentage (\%) \\
\hline Air Present & 55 & 91.67 \\
\hline Air Absent & 5 & 8.33 \\
\hline Total & $\mathbf{6 0}$ & $\mathbf{1 0 0 . 0 0}$ \\
\hline \multicolumn{2}{|c|}{ Table 9: Presence of air under diaphragm in patients with } \\
perforated duodenal ulcers
\end{tabular}

Chart 8. A. Graph showing investigation tests for perforated duodenal ulcer and 8. B. Pie diagram showing the presence and absence of radiological signs

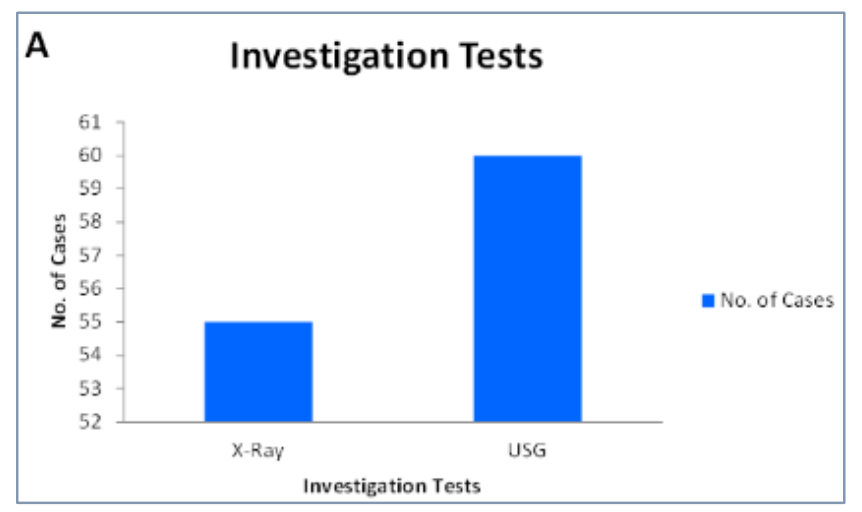

\section{B Radiological Signs}

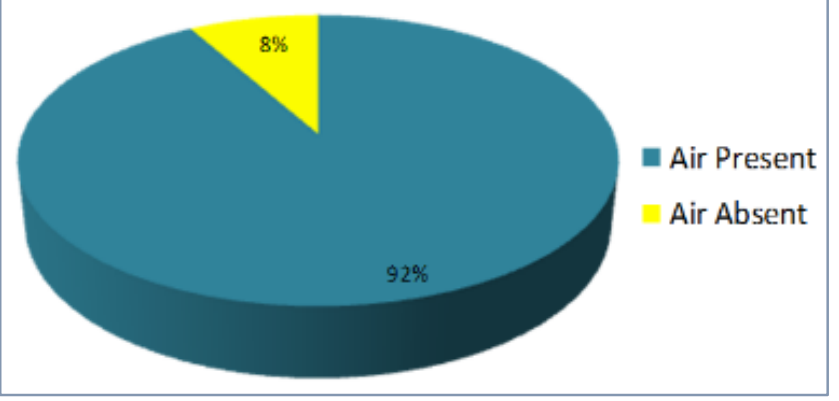




\begin{tabular}{|c|c|c|}
\hline Symptoms & No. of Cases & Percentage (\%) \\
\hline AP & 60 & 100.0 \\
\hline V & 13 & 21.7 \\
\hline F & 6 & 10.0 \\
\hline D & 60 & 100.0 \\
\hline
\end{tabular}

Table 10: Symptoms observed in duodenal ulcer perforation patient (AP-abdominal pain, V-vomiting, $F$ fever, and D-distension)

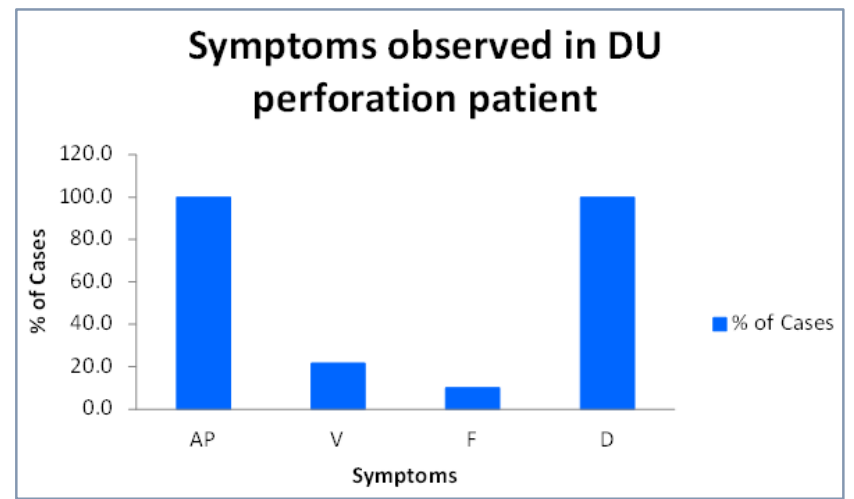

Chart 9: Symptoms observed in DU perforation patient

\begin{tabular}{|c|c|c|}
\hline Signs & No. of Cases & Percentage (\%) \\
\hline G/R & 60 & 100.0 \\
\hline BS & 60 & 100.0 \\
\hline DM & 6 & 10.0 \\
\hline HTN & 9 & 15.0 \\
\hline Shock & 8 & 13.3 \\
\hline $\begin{array}{c}\text { Table 11: Signs observed in DU perforated patient (G/R- } \\
\text { Guarding and Rigidity, BS-Bowel sound, DM-Diabetes } \\
\text { mellitus, HTN-Hypertension) }\end{array}$ \\
\hline \multicolumn{3}{|c}{} \\
\hline
\end{tabular}

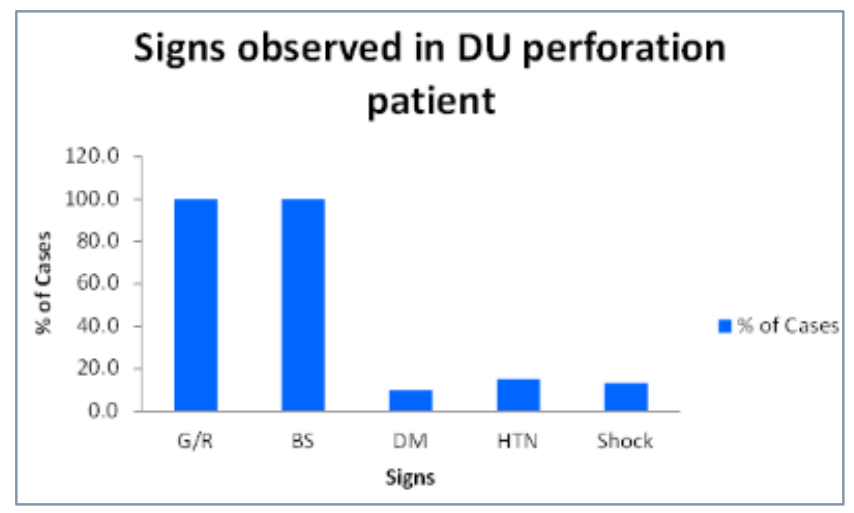

Chart 10: Signs observed in DU perforation patient

Management:

\begin{tabular}{|c|c|c|}
\hline Surgery & $\begin{array}{l}\text { No. of } \\
\text { Cases }\end{array}$ & Percentage (\%) \\
\hline SC \& OP & 55 & 91.67 \\
\hline TVGJ & 2 & 3.33 \\
\hline B/L Flank Drain & 2 & 3.33 \\
\hline Conservative & 1 & 1.67 \\
\hline Total & 60 & 100.00 \\
\hline \multicolumn{3}{|c|}{$\begin{array}{c}\text { Table 12: Surgical and conservative treatment of } \\
\text { perforated duodenal ulcer }\end{array}$} \\
\hline
\end{tabular}

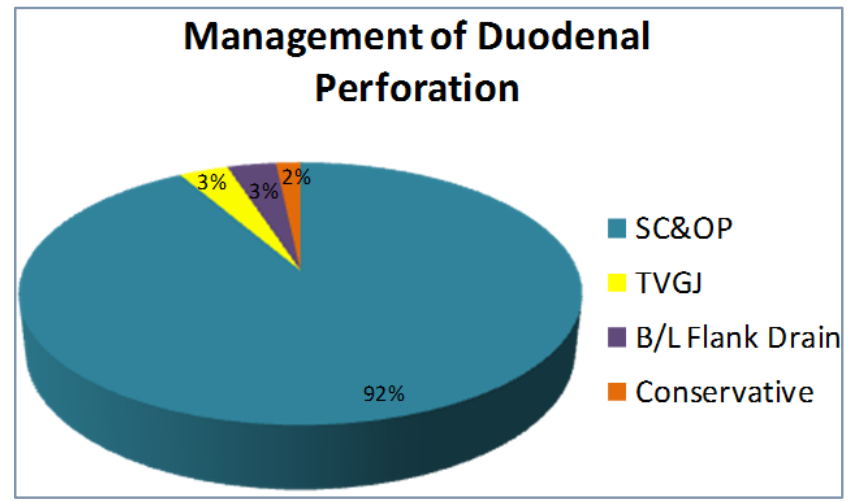

Chart 11: Pie diagram showing management of duodenal

Postoperative Complications:

\begin{tabular}{|c|c|c|c|}
\hline Procedure & No. of Cases & Mortality & Morbidity \\
\hline Operative & 59 & 7 & 6 \\
\hline Conservative & 1 & 0 & 0 \\
\hline Total & $\mathbf{6 0}$ & $\mathbf{7}$ & $\mathbf{6}$ \\
\hline
\end{tabular}

Table 13: Post-operative complications (X2-0.21, p>0.05 $(p=0.578)$

Chart 12: A. Outcome of operative and conservative method and B. Post-operative complications.
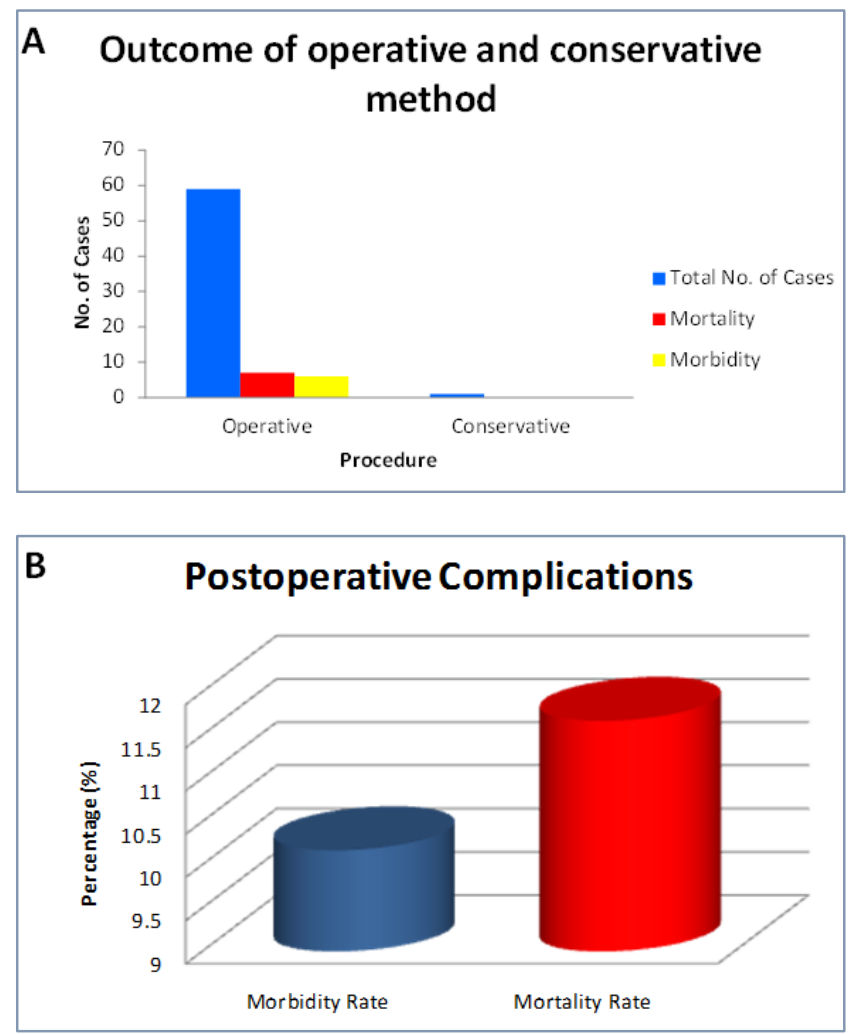

Duration of Stay:

\begin{tabular}{|c|c|c|}
\hline DOS (days) & No. of Cases & Percentage (\%) \\
\hline$<\mathbf{5}$ & 8 & 13.3 \\
\hline $\mathbf{6}$ to 10 & 49 & 81.7 \\
\hline$>\mathbf{1 0}$ & 3 & 5.0 \\
\hline Total & 60 & 100.0 \\
\hline Table 14: Duration of stay (DOS) in hospital after the \\
treatment of DU perforation \\
\hline
\end{tabular}




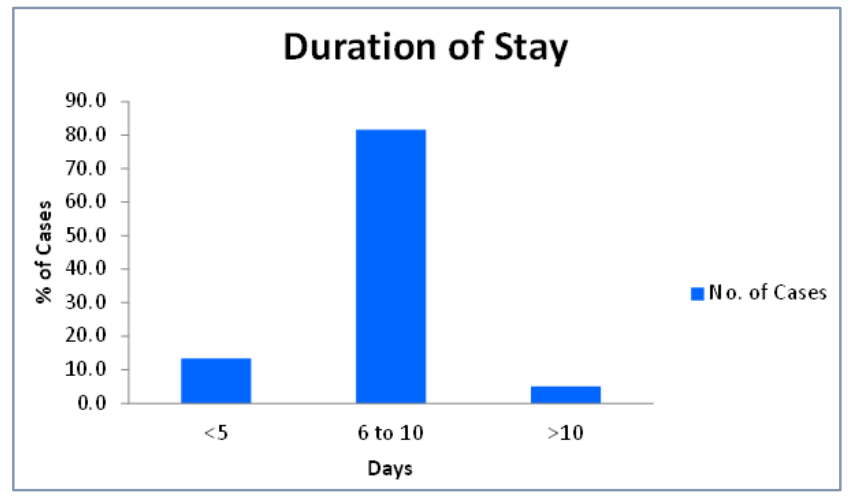

Chart 13: Duration of stay in hospital after treatment of $D U$ perforation

DISCUSSION: Duodenal ulcer is a type of peptic ulcer disease that destroys the lining of the duodenum. Duodenal perforation, complication of duodenal ulcer, is one of the commonest surgical emergencies requiring hospitalization and early management. Perforated duodenal ulcer remains a surgical emergency but nowadays it rarely results in death. The discussion is based on the analysis of data pertaining to 60 cases of perforated duodenal ulcers.

AGE: The age of patients in this study is ranging from 18 to more than 60 years. The peak age incidence was between 40 and 49 years.

\begin{tabular}{|c|c|c|}
\hline Author & Year & $\begin{array}{c}\text { Peak age incidence } \\
\text { (years) }\end{array}$ \\
\hline Samuel J et al. & 1953 & $30-60$ \\
\hline Debaley et al. & 1990 & $>50$ \\
\hline M.C.Dandpat et al. & 1991 & $20-40$ \\
\hline Ramesh C et al. & 1995 & $30-50$ \\
\hline Hannah et al. & 2005 & $31-40$ \\
\hline Kalpesh Jani et al. & 2006 & $30-50$ \\
\hline Taylor. & 2013 & $>50$ \\
\hline Present study & Table 15: Age Incidence \\
\hline \multicolumn{2}{|c|}{} \\
\hline
\end{tabular}

Gender: In the current study out of 60 cases, only 3 cases of females with perforated duodenal ulcers were observed. Our study found male predominance for perforated duodenal ulcers which correlates to the reported observation. The very low incidence of female patients with duodenal ulcer perforation in comparison to male incidence may be due to great difference in habits, social, economical, cultural activities and stress.

\begin{tabular}{|c|c|c|}
\hline Author & Year & $\begin{array}{c}\text { Male : Female } \\
\text { ratio }\end{array}$ \\
\hline Paul. H. Jordan. & 1995 & $26: 1$ \\
\hline Primrose N. John. & 2004 & $2: 1$ \\
\hline Rodney Maingot. & 1990 & $5: 1$ \\
\hline Present study & 2013 & $19: 1$ \\
\hline \multicolumn{2}{|c|}{ Table 16: General Incidence } \\
\hline
\end{tabular}

Socioeconomic Status: Perforation due to duodenal ulcer was common in lower socioeconomic group. Out of 60 cases of perforated duodenal ulcers, 39 cases $(65 \%)$ belonged to lower socioeconomic status.
Personal Habits: In the present study, all 57 males were either indulged with smoking $(40 \%)$ or alcohol $(30 \%)$ or both $(25 \%)$. The present study clearly reflects an increasing incidence of the duodenal ulcer perforations among alcoholics and smokers.

History of Acid Peptic Disease: In the present study, out of 60 cases 36 patients $(60 \%)$ had previous history of peptic ulceration. In the study conducted by George Stain et al, 75\% patients had past history of peptic ulceration.

History of Drug Intake: The analysis of 60 cases of perforation in the current study revealed that the intake of NSAIDs increases the incidence of the duodenal ulcer perforation. From the present study, NSAIDs intake was associated with $26.67 \%$ of patients with duodenal ulcer perforation. Moreover it was observed that the geriatric patients ( $>60$ years) with history of NSAIDs intake were at increased risk of duodenal ulcer perforation. $37.5 \%$ of geriatric patients had the history of NSAIDs intake. NSAIDs intake significantly increased with the age.

Seasonal Trends: In the current study the maximum incidence of perforation was during Feburary to September (54\%). But the rate of occurrence of duodenal ulcer perforations was significantly high during winter (October to January). During the four months of the winter $33(66 \%)$ cases of duodenal ulcer perforation were observed.

\begin{tabular}{|c|c|c|}
\hline Author & Year & Season of Perforation \\
\hline Bloom et al. & 1974 & Winter \\
\hline Present study & 2013 & Winter \\
\hline \multicolumn{2}{|c|}{ Table : 17 Seasonal Trend } \\
\hline
\end{tabular}

Radiological Signs: All patients in the present study were subjected to plain X-ray abdomen in erect position. Out of 60 cases studied, 55 patients $(91.67 \%)$ were found with pneumo-peritoneum.

\begin{tabular}{|c|c|c|}
\hline Study & Year & Pneumoperitoneum \\
\hline Shaffer study. & 1992 & $70 \%$ \\
\hline Present study & 2013 & $91.67 \%$ \\
\hline \multicolumn{2}{|c|}{ Table 18: Presence of pneumoperitoneum } \\
\hline
\end{tabular}

Duration of Symptoms: In the present study the duration of symptoms (Pain/vomiting /distension/constipation or diarrhea/injury/fever) before presentation to the hospital was found to be 1.49 days (1-4 days). This was mainly because most of the patients were initially treated at nursing clinics, primary care centers and then referred to our hospital. If they arrived straight to our hospital, they would have been operated earlier and the time lag would have been decreased. Abdominal pain and diarrhea were present in all patients.

Delay: The delay in taking up the patient for emergency operation was 3.67 hours (2-7 hours). Patients who presented with shock needed intense resuscitation and after improving their general condition, they were shifted to emergency operation.

Management: 59 patients were subjected to surgical treatment (SC+OP, B/L Flank Drainage and GJ+TV). One patient was maintained conservatively because field of perforation was suspected and he maintained his vitals. His response to drug therapy was positive and he recovered. 
Hospital Stay: Patient who lapsed a longer time after operation contributed to increase in hospital stay by wound infection and increased time for improvement in general condition. Increase in age and conservative management also contributed to prolonged hospital stay. Average duration of the hospital stay was found to be 8.05 days (2-16 days).

Postoperative Complications: In the present study, 47 patients with duodenal ulcer perforation had smooth recovery. Out of 60 cases, 13 patients had suffered from various complications such as wound infection. Seven of thirteen patients with post-operative complications expired. Patients who presented late (2 days or more) to emergency surgical ward and who had comorbid illness had increased rate of wound infection.

Mortality: From the present study following prognostic factors in duodenal ulcer perforation can be concluded:

1. Age.

2. Associated comorbid illness.

3. Time delay between onset of symptoms and admission to hospital.

4. Patient general condition at the time of presentation.

Nine patients belonging to age group of more than 60 years were associated with comorbid illness (Diabetes Mellitus, Hypertension). Seven patients of this age group where presented with septicemia shock. Mortality rate in the age group of above 60 years is as high as $44.44 \%$.

There were three patients in the age group of 40 to 49 years which were associated with comorbid illness and presented with shock. The mortality rate in this age group was $20 \%$. A detailed study on outcome of non-operative management was not carried out because patients were lost for follow-up. The observations in this group were incidentally made out.

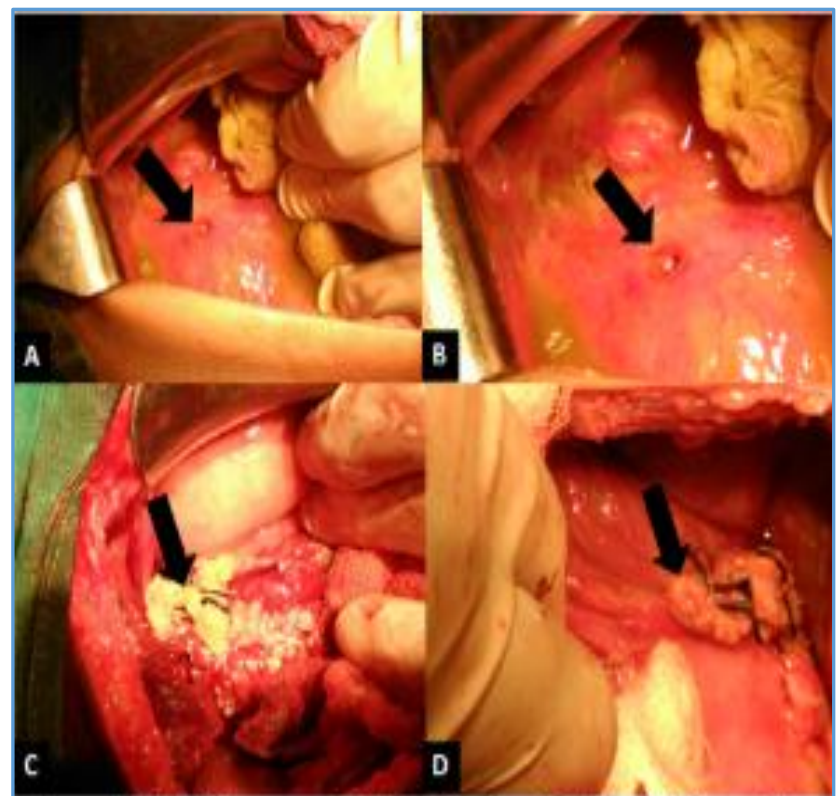

Figure 17: A. Black arrow points to duodenal perforation; $B$. Enlarged view duodenal perforation; C. Omeatal patch and D. Enlarged vlew of omental patch.

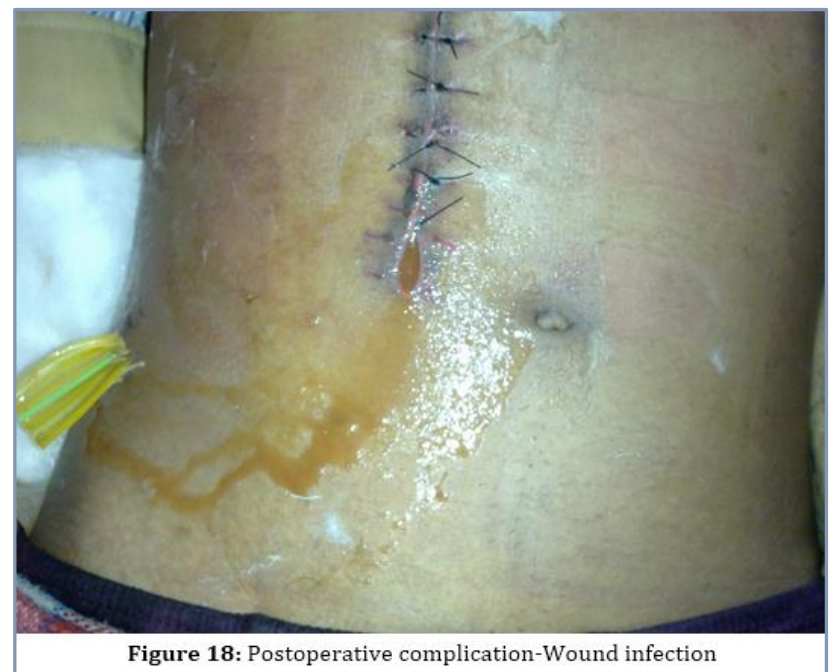

CONCLUSION: A series of sixty cases duodenal perforations were studied and analyzed at Department of Surgery, Basaveshwara Teaching and General Hospital, Gulbarga Karnataka during the period of Nov 2011-Sep. 2013.

The following is the list of the conclusions drawn after the study:

1. Duodenal ulcer perforation is one of the most common acute abdominal emergencies.

2. Duodenal ulcer perforation was more common in the age group of 40-49 years.

3. In this study the male: female ratio was found to be19:1.

4. Duodenal peroration was common in lower socioeconomic group.

5. The associated risk factors are found to be smoking, alcohol intake, NSAIDs intake and previous history of acid peptic disease.

6. Duodenal perforation cases were high during winter season.

7. Symptoms like abdominal pain and diarrhea were present in all patients with DU perforation.

8. Signs of $G / R$ and $B S$ were common in patients with DU perforation

9. Wound infection was common post-operative complications.

10. Mortality rate was higher in case of geriatric patients with comorbid illness.

11. Mortality rate in the age group of above 60 years is as high as $44.44 \%$.

12. Prognostic factors were

a) Age.

b) Comorbid illness.

c) Duration of symptoms.

d) Delay in taking up the patient for emergency operation.

e) Patient's general condition at the time of presentation.

\section{BIBLIOGRAPHY:}

1. Bertleff MJ, Lange JF. Perforated peptic ulcer disease: a review of history and treatment. Dig Surg. 2010 Aug; 27(3):161-169.

2. Maingot's abdominal operations-10th editin. Haile $\mathrm{T}$. Debas, Sean J. Molvitill, Appleton \& Lange Vol.

I: p 983-984. 
3. Wormsley KG. The pathophysiology of duodenal ulceration. Gut. 1974 January; 15(1): 59-81.

4. Madiba TE, Nair R, Mulaudzi TV, Thomson SR. Perforated gastric ulcer - reappraisal of surgical options. South African Journal of Surgery. 2005; 43(3): 58-60.
5. Tadataka Y, David AH, Neil K, Loren L, Chung O, Don PW. Textbook of Gastroenterology. 2003; 4th Edition. Lippincott Williams \& Wilkins. 